\title{
PENGARUH INTERAKSI TEMAN SEBAYA TERHADAP KENAKALAN REMAJA DI SMAN 1 CICALENGKA, KECAMATAN CICALENGKA, KABUPATEN BANDUNG
}

\author{
Oleh: \\ TRESNA DARMAWAN, R. NUNUNG NURWATI, ARIE SURYA GUTAMA \\ Email: \\ tresnadarmawan21@gmail.com
}

\begin{abstract}
Abstrak
Masa remaja merupakan masa transisi dari kanak-kanak ke masa dewasa. Secara umum dapat di ketahui pada masa transisi tidak menutup kemungkinan akan terjadi pergolakan-pergolakan fisik, psikis dan sosial. Keluarga merupakan fondasi primer bagi pekerkembangan remaja. Persepsi remaja terhadap keharmonisan keluarga yang diwujudkan dalam hubungan keluarga yang baik dan suasana rumah yang menyokong perkembangan remaja, sehingga remaja menjadi orang dewasa yang bertanggung jawab dan terhindar dari perbuatan anti sosial/ amoral. Selain sersosialisasi di lingkungan keluagam remaja melakukan salah satu bentuk sosialisasi yang dengan taman sebaya. Remaja memiliki teman sebaya yang melakukan kenakalan meningkatkan resiko untuk enjadi pelaku kenakalan. Teman yang dipilih akan sangat menentukan remaja untuk berbuat.

Populasi penelitian ini adalah siswa SMAN 1 Cicalengka, Kab.Bandung. sampel penelitian ini berjumlah 80 orang yang diperoleh dengan teknik Cluster ramdom sampling dengan meramdom lima kelas didapat dua kelas yang masing masing-masing berjumlah 40 siswa. Alat pengumpul data yang digunakan dalam penelitian ini adalah Skala Konformitas Teman Sebaya yang dengan menggunakan metode Skala Linkert. Penelitian ini untuk melihat apakah ada hubungan kenakalan remaja dengan interaksi teman sebaya.
\end{abstract}

Kata Kunci : Kenakalan Remaja, konformitas teman sebaya

\section{Abstract}

Adolescence is a period of transition from childhood to adulthood. In general it can be in the know in the transition period will possibly happen upheavals of physical, psychological and social. The family is the primary foundation for pekerkembangan adolescents. Adolescent perception of the family harmony embodied in a good family relationship and atmosphere of the house which underpins the development of adolescents, so that teenagers become adults who are responsible and avoid antisocial actions / immoral. Besides sersosialisasi keluagam teenagers in the neighborhood doing one form of peer socialization with park. Teens have peers who did delinquency increases the risk for delinquency enjadi offender. The selected friend will be very decisive teenagers to do.

This study population is students of SMAN 1 Cicalengka, Kab.Bandung. This research sample totaled 80 obtained by Cluster random sampling technique with meramdom five classes each obtained two classes each of 40 students. Data collection tool used in this study was Conformity Scale Peers that by using the Scale method Linkert. This study was to see whether there is a relationship of juvenile delinquency with peer interaction. 
Keywords : juvenile delinquency, conformity peers

\section{PENDAHULUAN}

Masalah remaja adalah suatu masalah yang sebenarnya menarik untuk dibicarakan, terlebih akhir-akhir ini timbul akhibat negatif yang sangat mencemaskan yang akan membawa kehanuran bagi remaja itu sendiri dan masyarakat pada umumnya. Remaja adalah bagian penting dari generasi muda Indonesia dan merupakan tumpuhan harapan bagi masa depan bangsa.

Sugiyanto (1995:32) menjelaskan, "Adolesensi atau remaja adalah individuindividu yang berusia 10 sampai 18 tahun untuk perempuan atau berusia 12 sampai 20 tahun untuk laki-laki. Masa adolesensi merupakan masa transisi atau peralihan dari masa anak-anak untuk menjadi dewasa." Harold Alberty dalam Makmun (1981:55) menjelaskan bahwa periode masa remaja sebagai "Suatu periode dalam perkembangan yang dijalani seseorang yang terbentang semenjak berakhirnya masa kanak-kanaknya sampai datangnya awal masa dewasanya." Lebih lanjut Makmun (1981:55) menjelaskan, "Secara tentatif pula ahli umumnya sependapat bahwa rentangan masa remaja itu berlangsung dari sekitar 11 - 13 tahun sampai 18 - 20 tahun menurut ukuran umur kalender kelahiran seseorang."

Remaja adalah masa peralihan, seseorang telah meninggalkan usia anak-anak yang penuh kelemahan dan ketergantungan tanpa memikul sesuatu tanggung jawab , menuju kepada usia dewasa yang sibuk dengan tanggung jawab penuh.

Data yang di realease oleh BKKBN (Badan Kependudukan dan Keluarga Berencana Nasional) menunjukan "Jumlah remaja di Indonesia mencapai $30 \%$ dari jumlah penduduk, jadi sekitar 1.2 juta jiwa “. Adapun Hasil Penelitian BNN bekerja sama dengan UI menunjukkan :

1. Jumlah penyalahguna narkoba sebesar $1,5 \%$ dari populasi atau 3,2 juta orang, terdiri dari $69 \%$ kelompok teratur pakai dan $31 \%$ kelompok pecandu dengan proporsi laki-laki sebesar $79 \%$, perempuan $21 \%$.

2. Kelompok teratur pakai terdiri dari penyalahguna ganja $71 \%$, shabu $50 \%$, ekstasi $42 \%$ dan obat penenang $22 \%$.

3. Kelompok pecandu terdiri dari penyalahguna ganja $75 \%$, heroin / putaw $62 \%$, shabu $57 \%$, ekstasi $34 \%$ dan obat penenang $25 \%$.

4. Penyalahguna Narkoba Dengan Suntikan (IDU) sebesar 56\% (572.000 orang) dengan kisaran 515.000 sampai 630.000 orang.

5. Beban ekonomi terbesar adalah untuk pembelian / konsumsi narkoba yaitu sebesar Rp. 11,3 triliun.

6. Angka kematian (Mortality) pecandu 15.00 orang meninggal dalam 1 tahun.

Menurut Koordinator Senior Mitra Citra Remaja, Perkumpulan Keluarga Berencana Indonesia (MCR PKBI), Dian Marviana mengatakan perilaku seksual di kalangan remaja Bandung sudah harus diperhatikan berbagai pihak. Berdasarkan data yang diupdate MCR PKBI selama 6 bulan sekali, data terakhir angka seks bebas di Bandung mencapai $12 \%$.

Berdasarkan survey Badan Koordinasi Keluarga Berencana Nasional (BKKBN) tahun 2008, remaja Kota Bandung usia 15-14 tahun sebanyak $57 \%$ telah melakukan hubungan seksual di luar nikah. Sementara hasil penelitian Klinik Mawar PKBI melalui Data Collections Project Achievement (DCPA) dari data sample 100 orang Wanita Penjaja Seks (WPJ) yang ada di Bandung, 49\% remaja menjadi WPS, 92\% nya merupakan remaja putus sekolah. Data-data yang dihimpun dari mitra-mitra PKBI pada periode Juli 2011Maret 2012 menunjukkan bahwa 30\% dari 20 
ribu pekerja seks berusia dibawah 24 tahun. Angka inveksi HIV tertinggi juga ada pada kelompok usia muda, 20-19 tahun.

Hasil survey perilaku seks di kalangan remaja menunjukkan Bandung meraih angka tertinggi sebesar 54\% remaja di Bandung melakukan hubungan seksual di luar nikah. Dibanding tiga kota lainnya yang ikut disurvey, Bandung merupakan kota dengan angka tertinggi, melebihi Jakarta yang angkanya lebih rendah yakni, 51\%, Surabaya 47\%, sementara Medan 52\%.

\section{PEMBAHASAN}

Ditinjau dari psikologi perkembangan, masa remaja merupakan masa transisi dari kanak-kanak kemasa dewasa. Secara umum dapat diketahui pada masa transisi tidak menutup kemungkinan akan terjadi pergolakan-pergolakan fisik, psikis dan sosial dalam rangka remaja mencari jati dirinya.

Masa remaja merupakan masa transisi, usianya berkisar antara 13 sampai 17 tahun atau biasa disebut dengan usia belasan yang tidak menyenangkan. Pada masa remaja juga perubahan pada dirinya baik secara fisik, psikis maupun secara sosial ( Hurlock, 1999)

Pada masa transisi tersebut kemungkinan dapat menimbulkan masa kritis, yang ditantai dengan kecenderungan munculnya perilaku menyimpang. Pada kondisi tertentu perilaku menyimpang. Pada kondisi tertentu perilaku menyimpang tersebut akan menjadi perilaku yang mengganggu (ekowarni, 1993). Melihat kondisi tersebut apabila didukung oleh lingkungan yang kurang kondusif dan kondisi kepribadian yang kurang matang akan menjadi pemicu timbulnya berbagai penyimpangan perilaku dan perbuatan-perbuatan negative yang melanggar aturan dan norma yang ada di masyarakat yang biasanya di sebut dengan kenakalan remaja.

Manusia adalah mahluk yang berkelompok, dan semakin jauh ia mengenal dirinya, maka akan semakin jauh pula ia mengenal masyarkat. Manusia tidak bisa hidup sendiri, melainkan manusia hidup berdampingan dengan manusia-manusia lainya. Individu tidak bisa di pisahkan dari kelompok, bahwa individu-individu hanya akan dapat mencapai pengembangan potensi mereka yang setinggi-tingginya serta perasaan harga diri yang kuat, memalui partisipasi mereka dalam kehidupan kelompok.

Kenakalan remaja tidak telepas dari penggaruh orang-orang di sekitarnya, penggaruh-penggaruh dari lingkungannya juga akan membuat sesorang terpenggaruh untuk melakukan kenakalan remaja. Kenakalan remaja juga tidak lepas dari peran kelompok dimana kelompok ini adalah teman-teman sebaya dari remaja tersebut.

Kelompok dalam perspektif Pekerjaan Sosial dipandang sebagai sekumpulan orang yang saling berinteraksi satu sama lain dan membentuk suatu kesatuan yang terpisah dan berbeda dari kesatuan-kesatan lainya.

Social group work adalah suatu metode untuk bekerja dengan, menghadapi orangorang didalam suatu kelompok, guna peningkatan kemampuan untuk melaksanakan fungsi sosial; serta guna pencapaian tujuantujuan yang secara sosial dianggap baik ( Soetarso, pengantar kesejahteraan sosial, 1976). Bimbingan sosial kelompok didasarkan atas pengetahuan mengenai kebutuhankebutuhan manusia untuk berhubungan satu sama lain, dan adanya saling ketergantungan di antara mereka.

\section{DAFTAR PUSTAKA}

Budhi Wibhawa, Santoso T Raharjo, Meilany Budhiarti 2010. Pengantar Pekerjaan Sosial. Bandung ; Widya Padjadjaran

Soerjono Soekanto, "Sosiologi Suatu Pengantar", (Jakarta: PT. RajaGrafindo Persada, 1982)

Hurlock, Elizabeth 1997. Psikologi Perkembangan. Jakarta : Erlangga

Hurlock, E.B 1992. Developmental Psycology 
Santock, 2002. Life Span Develompment.

Jakarta : Erlangga

Suhato Edi , 2007, Paragma Ilmu

Kesejahteraan Sosial, Bandung ;

AlfaBetha 